\title{
HLA-Association in patients with intolerance to mercury and other metals in dental
} materials

\author{
J. Procházkováa,*, J. Bártováa ${ }^{a}$ E. Ivašková ${ }^{b}$, \\ L. Kupkováb, I. Šterzl ${ }^{\mathrm{c}}$ and V.D.M. Stejskal ${ }^{\mathrm{d}}$ \\ anstitute of Dental Research, Vinohradská 48, 12060 \\ Prague 2, Czech Republic \\ b IKEM, National HLA Centre, Vídeňská 800, 14000 \\ Prague 4, Czech Republic \\ ' Institute of Endocrinology, Národní 8, 11694 Prague \\ 1, Czech Republic \\ ${ }^{\mathrm{d}}$ Department of Clinical Chemistry, Danderyds \\ Hospital and Karolinska Institute, Stockholm, Sweden
}

Received 5 March 2000

A group of selected 25 patients with serious intolerance to heavy metals used for dental restoration were examined for HLA antigens. A significant increase for HLA - B37, B47 and DR4 was found. The value of the relative risk is not significant after correction for the number of antigens tested and therefore further studies of more patients are needed.

Keywords: HLA antigens, metal intolerance, dental materials

\section{Introduction}

Metals in the form of biologically active substances are components of various dental materials, including supportive implants. In spite of declared "biocompatibility", such metals (aluminium, chromium, cobalt, mercury, nickel, platinum, steel, vanadium, and zinc) if present in dental materials, can induce serious local or atopic allergic reactions in sensitive patients [15].

Heavy metals present in dental materials were recognised as responsible for atopic eczema [4], nickel hypersensitivity was related to periodontitis [3] and pro-

* Correspondence to: Dr. Jarmila Procházková, Institute of Dental Research, General Faculty Hospital of Charles University Prague, Vinohradská 48, 12060 Prague 2, Czech Republic. Tel.: +4202 24256718; Fax: +4202 24247034; E-mail: vuspraha@mbox.vol.cz. fessional allergy to cobalt chromium dust in dental technicians was described [12]. Potolicchio et al. [8] reviewed data on mechanisms by which metals induce allergic or autoimmune-like reactions and demonstrated that HLA-DP2 molecules do bind cobalt specifically. Therefore prognosis and monitoring of allergic reactions to metal dental materials are theoretically and practically highly relevant.

Diagnostic tests for metal intolerance are fairly restricted. Skin tests are no doubt a diagnostic method for allergies but they also have some disadvantages. These include a possibility that negative skin reactions are not necessarily reliable as the skin might not be always the organ which is metal sensitive. On the other hand, skin reactions might be false positive if the tested materials are highly irritating. About 10 to 20 per cent of persons whose skin tests to the tested allergen is positive do not in fact show any allergic reactions to the given allergen [2,7]. Allergic people can also suffer false negative skin test reactions for reasons which remain unclear [7].

For diagnostic purposes the test system "Memory Lymphocyte Immune Stimulation Assay" (Melisa ${ }^{\text {TM }}$, Sweden) is of potential importance. The test is based on evaluation of memory cell proliferation after incubation with heavy metal salt $[13,14]$. This test is used in our study for diagnosis of metal intolerance.

Allelic components of the Major Histocompatibility Complex (MHC) are associated with various diseases and deviation of the immune response, including allergies to heavy metals [15]. Aten [1] demonstrated that the induction of autoimmunity by mercuric chloride is in rats related MHC Class II haplotype. Expression of MHC Class I molecules in Brown-Norway rats is modified by $\mathrm{HgCl}_{2}$ [10] and $\mathrm{HgCl}_{2}$ induced systemic autoimmunity is due to direct effect of this metal compound on activation potentials of $\mathrm{T}$ and $\mathrm{B}$ cells [9]. Jiang and Möller [6] analysed the unresponsiveness to $\mathrm{HgCl}_{2}$ of CD4 $\mathrm{T}$ cells in non-responder strains. Association of HLA-Class I and II with pe- 
Table 1

Results of the Melisa ${ }^{\mathrm{TM}}$ test. SI are shown only for positive values. Negative values are given as *. For some the patients not all metals were tested (empty squares). The selection of metals to which sensitivity was tested was based on anamnestic information

\begin{tabular}{|c|c|c|c|c|c|c|c|c|c|c|c|c|c|c|}
\hline Patient & $\mathrm{Ag}$ & $\mathrm{Au}$ & $\mathrm{Cd}$ & $\mathrm{Co}$ & $\mathrm{Cr}$ & $\mathrm{Cu}$ & $\mathrm{Fe}$ & $\mathrm{Hg}$ & $\mathrm{Ni}$ & $\mathrm{Pb}$ & $\mathrm{Pd}$ & $\mathrm{Pt}$ & $\mathrm{Sn}$ & $\mathrm{Ti}$ \\
\hline 1 & & $*$ & $*$ & & $*$ & $*$ & & 3.55 & $*$ & $*$ & $*$ & & & $*$ \\
\hline 2 & $*$ & $*$ & & & & $*$ & & 11.8 & & & $*$ & $*$ & & \\
\hline 3 & $*$ & $*$ & 2.26 & $*$ & $*$ & $*$ & & 2.15 & $*$ & 3.28 & $*$ & & & $*$ \\
\hline 4 & & $*$ & 11.5 & & & 2.6 & & 14.5 & 14.31 & $*$ & $*$ & $*$ & & $*$ \\
\hline 5 & 7.8 & $*$ & $*$ & 2.34 & 2.14 & $*$ & & 10.2 & $*$ & & $*$ & $*$ & & \\
\hline 6 & $*$ & 3.25 & $*$ & $*$ & & $*$ & 2.96 & 8.53 & 2.36 & $*$ & & & & \\
\hline 7 & $*$ & & $*$ & $*$ & $*$ & $*$ & & 3.31 & $*$ & $*$ & & $*$ & & \\
\hline 8 & $*$ & 6.68 & 7.23 & 2.99 & $*$ & $*$ & 4.43 & 6.15 & 18.81 & 2.28 & $*$ & $*$ & 4.3 & 2.78 \\
\hline 9 & $*$ & 2.34 & $*$ & & $*$ & $*$ & $*$ & 2.6 & 2.84 & & $*$ & $*$ & 2.42 & 2.38 \\
\hline 10 & & $*$ & $*$ & & & $*$ & $*$ & 3.07 & & $*$ & $*$ & $*$ & $*$ & $*$ \\
\hline 11 & $*$ & $*$ & 4.01 & $*$ & $*$ & & & 29.95 & 3.57 & & & & $*$ & \\
\hline 12 & $*$ & $*$ & $*$ & $*$ & $*$ & $*$ & 2.67 & 14.45 & $*$ & $*$ & & & $*$ & \\
\hline 13 & $*$ & $*$ & $*$ & $*$ & $*$ & & & 5.77 & $*$ & $*$ & $*$ & & $*$ & \\
\hline 14 & $*$ & $*$ & 5.31 & $*$ & $*$ & $*$ & $*$ & 3.08 & 3.88 & 3.58 & 3.32 & & 2.06 & \\
\hline 15 & $*$ & $*$ & $*$ & $*$ & $*$ & $*$ & $*$ & 2.08 & $*$ & $*$ & $*$ & 2.22 & & $*$ \\
\hline 16 & 2.84 & $*$ & $*$ & $*$ & $*$ & & 3.91 & 10.64 & $*$ & $*$ & $*$ & $*$ & & $*$ \\
\hline 17 & & 2.72 & $*$ & & 3.31 & & & 57.52 & $*$ & $*$ & 2.11 & & 7.05 & $*$ \\
\hline 18 & $*$ & 2.36 & 12.33 & $*$ & 8.5 & $*$ & $*$ & 2.92 & 17.18 & 2.47 & 3.61 & 2.65 & $*$ & $*$ \\
\hline 19 & $*$ & $*$ & $*$ & & $*$ & $*$ & & 2.4 & & $*$ & $*$ & $*$ & $*$ & $*$ \\
\hline 20 & $*$ & 4.28 & & $*$ & $*$ & $*$ & 2.93 & 3.24 & 16.45 & 2.61 & 9.44 & 4.88 & 5.49 & 17.88 \\
\hline 21 & $*$ & & & & & & & 2.88 & & & & & & $*$ \\
\hline 22 & 2.61 & & $*$ & & $*$ & $*$ & & 14.15 & 11.14 & $*$ & $*$ & & 21.74 & \\
\hline 23 & $*$ & $*$ & 2.1 & $*$ & $*$ & $*$ & $*$ & 11.96 & $*$ & 7.56 & $*$ & $*$ & $*$ & $*$ \\
\hline 24 & 4.04 & $*$ & 6.62 & $*$ & $*$ & $*$ & & 6.16 & 5.1 & & $*$ & & $*$ & 3.57 \\
\hline 25 & $*$ & $*$ & $*$ & $*$ & $*$ & $*$ & $*$ & 2.01 & $*$ & 2.56 & $*$ & $*$ & $*$ & $*$ \\
\hline
\end{tabular}

riodontitis was recorded by Takashiba et al. [16] and Terasaki et al. [17].

Studies on HLA association with heavy metal intolerance or allergy are almost absent. Saito [11] described a significant increase of DR4 frequency (Relative risk $=13,27$ ) in Japanese patients sensitive for palladium.

In our work we studied the HLA phenotypes in 25 patients with severe metal intolerance. These have been patients with serious allergic reactions examined at the Institute of Dental Research, Prague for consultation from the whole area of the Czech Republic.

\section{Material and methods}

PATIENTS: Patients were identified as having local signs of intolerance to dental materials such as ptyalism, paraesthesia of the tongue and oral mucosa, ulcerations of the gingival tissue and oral mucous membrane and pigmentation following deposition of metals in the gum from amalgam fillings and other metal dental materials combined with general inconveniences as chronic fatigue, nausea, vomiting, head ache, increased perspiration, breathing discomfort. All these symptoms were related with den- tal interventions most frequently with dental fillings made by amalgam alloys and prosthetic reconstruction which included dental metal alloys. Allergy to metal was examined by the Melisa ${ }^{\mathrm{TM}}$ test [13] for the following metal compounds tested as allergens: $\mathrm{Al}_{2} \mathrm{O}_{3}, \mathrm{CH}_{3} \mathrm{COOAg}, \mathrm{AuNa}_{3}\left(\mathrm{~S}_{2} \mathrm{O}_{3}\right)_{2}, \mathrm{CdCl}_{2}, \mathrm{CoCl}_{2}$, $\mathrm{CrCl}_{3}, \mathrm{CuSO}_{4}, \mathrm{Fe}_{2} \mathrm{O}_{3}, \mathrm{HgCl}_{2}$, phenylmercuryacetate, methylmercurychloride, ethylmercurychloride, thiomersal, $\mathrm{NiCl}_{2}, \mathrm{~Pb}\left(\mathrm{NO}_{3}\right)_{2}, \mathrm{PdCl}_{2}, \mathrm{PtCl}_{4}, \mathrm{SnCl}_{2}$ and $\mathrm{TiO}_{2}$.

The stimulation index (SI) was calculated as the ratio of stimulated culture and average of values from nonstimulated cultures. According to values obtained from positive controls (samples stimulated with the polyclonal stimulator - Pokeweed mitogen - from Phytolacca americana), the SI was evaluated as negative (SI $<2$ ), positive (SI 2.0-3.0) and strong positive (SI > 3.0). The stimulation values (cpm) are expressed as count of ${ }^{3} \mathrm{H}$-thymidine incorporation per minute.

Typing of HLA antigens was performed by routine serological techniques (standard NIH microlymphocytotoxicity test for Class I and prolonged incubation of B-lymphocytes isolated from PBL for Class II antigens) [5,17]. In total 47 HLA antigens were tested by sets of specific anti-HLA antisera.

Statistical evaluation was performed by the Fisher's exact test. $P<0.05$ are considered as significant. 
Table 2

Increased and decreased values of relative risk for chosen HLA antigens in 25 patients with heavy metal intolerance*

\begin{tabular}{ccccc}
\hline HLA antigens & $\begin{array}{c}\text { Frequency }(\%) \\
\text { in patients }\end{array}$ & $\begin{array}{c}\text { Frequency }(\%) \\
\text { in controls }\end{array}$ & $\begin{array}{c}\text { Probability } \\
(\mathrm{P})\end{array}$ & $\begin{array}{c}\text { Relative } \\
\text { risk }\end{array}$ \\
\hline B 27 & 16.0 & 9.6 & 0.278 & 0.54 \\
B 37 & 12.00 & 3.1 & $0.010^{*}$ & 2.25 \\
B 47 & 8.0 & 1.5 & $0.007^{*}$ & 5.56 \\
DR 4 & 44.00 & 22.6 & $0.011^{*}$ & 2.87 \\
DR 7 & 12.00 & 29.4 & 0.056 & 0.33 \\
\hline
\end{tabular}

${ }^{*} P<0.05$

The frequency of HLA antigens in patients was compared with data obtained on the healthy (control) Czech population (mostly registered bone marrow donors) of 15,200 unrelated individuals. Reactivity to heavy metals was not tested in the control group, which is considered sufficiently large as to neglect potential systematic diseases.

\section{Results and discussion}

The results of the Melisa ${ }^{\mathrm{TM}}$ test (Table 1) confirm in all 25 patients sensitivity to heavy metals. Positive reaction to mercury was present in all patients (SI mostly strongly positive).

The results of HLA typing of the 25 patients showed increased frequencies (Relative risk $>0.5$ ) for 4 HLA antigens (B27, B37, B47, DR4) and a decreased value for DR7. The values for antigens HLA-B37,B47 and DR4 were statistically significant (Table 2).

These results provide an indication about the possible role of HLA molecules for intolerance to heavy metals. However the significance of the HLA associations has to be confirmed on larger groups of patients. Patients with unequivocal symptoms of sensitisation to heavy metals are not frequent. Saito [11] found no significant HLA association for mercury and nickel sensitive patients, however DR4 was significantly increased in palladium sensitive patients. The possible involvement of HLA Class II antigens is indicated by data on the role of Class II molecules in experimental models for sensitivity to mercury chloride $-\mathrm{HgCl}_{2}[1,6,9,10]$.

Because tolerance to heavy metals might be based on mechanism common to other allergic reactions the possible role of HLA molecules provide an approach for better understanding the mechanism involved.

\section{Acknowledgements}

The authors thank Dr. Pavol and Dr. Dagmar Iv ányi for their inestimable advice.
The project was supported by grants $3472-3$ and 3419-3, awarded by the Internal Grant Agency of the Ministry of Health of the Czech Republic.

\section{References}

[1] J. Aten, A. Veninga, E. deHeer, J. Rozing, P. Nieuwenhuis, P.J. Hoedemaeker and J.J. Weening, Susceptibility to the induction of either autoimmunity or immunosupression by mercuric chloride is related to the MHC class II haplotype, Eur. J. Immunol. 21 (1991), 611-616.

[2] I. Bohm, M. Brody and R. Bauer, Comparison of personal history with patch test results in metal allergy, J. Dermatol. 24 (1997), 510-513.

[3] G.J. Bruce and W.B. Hall, Nickel hypersensitivity-related periodontitis, Educ. Dent. 16 (1995), 180-186.

[4] G. Ionescu, Allergotoxische Einflüsse von Umweltschadstoffen bei Allergiekranken, Forsch. Komplementärmed 2 (1995), 2-8.

[5] E. Ivašková, Approvement of HLA antigens, in: Chosen diagnostic methods in medical immunology 1986, J. Procházková and C. John, eds, Avicenum, Prague, 1986, pp. 293-307.

[6] Y. Jiang and G. Möller, Unresponsiveness of CD4+ T cells from a non-responder strain to $\mathrm{HgCl}_{2}$ is not due to CD8+-mediated immunosupression: an analysis of the very early activation antigen CD69, Scand. J. Immunol. 44 (1996), 565-570.

[7] P. Panzner, Epicutanne tests, in: Platform for clinical immunology 1994, T. Fučková, J. Bartuňková, J. Litzman and P. Panzner, eds, RDI' PRESS and Agency KRIGL, Prague, 1994, pp. 112-113.

[8] I. Potolicchio, A. Festucci, P. Hausler and R. Sorrentino, HLADP molecules bind cobalt: a possible explanation for the genetic association with hard metal disease, Eur. J. Immunol. 29 (1999), 2140-2147.

[9] A. Roos, N. Claessen, J.J. Weening and J. Aten, Enhanced T lymphocyte expression of LFA-1, ICAM-1, and the TNF receptor family member $\mathrm{OX} 40$ in $\mathrm{HgCl}_{2}$-induced systemic autoimmunity, Scand. J. Immunol. 43 (1996), 507-518.

[10] A. Roos, E.J.M. Schilder-Tol, M.A. Chand, J.J. Weening and J. Aten, $\mathrm{HgCl}_{2}$ and $\mathrm{Il} 4$ differentially modify expression of major histocompatibility complex class II molecules RT1.B and RT1.D in B lymphocytes from Brown Norway and Lewis rats, Transplantation Proceedings 29 (1997), 1675-1676.

[11] K. Saito, Analysis of genetic factor of metal allergy; polymorphism of HLA-DR, DQ genes, Kokubyo Gakkai Zasshi 63 (1996), 53-69.

[12] A.I. Selden, B. Persson, S.I. Bornberger-Denkvardt, L.E. Windstrom and L.S. Bodin, Exposure to cobalt chromium dust 
and lung disorders in dental technicians, Thorax 50 (1995), 769-772.

[13] V.D.M. Stejskal, K. Cederbrandt, A. Lindvall and M. Forsbeck, MELISA - an in vitro tool for the study of metal allergy, Toxicol. in vitro 5 (1994), 991-1000.

[14] V.D.M. Stejskal, M. Forsbeck, K. Cederbrandt and O. Asteman, Mercury-specific lymphocytes: an indication of mercury allergy in man, J. Clin. Immunol. 16 (1996), 31-40.

[15] N. Suzuki, Metal allergy in dentistry: detection of allergen metals with X-ray fluorescence spectroscope and its applica- tion toward allergen elimination, Int. J. Prosthodent. 8 (1995), 351-359.

[16] S. Takashiba, S. Noji, F. Nishimura, H. Ohyama, H. Kurihara, Y. Namura, S. Tanigushi and Y. Murayama, Unique intronic variations of HLA-DQb gene in early onset periodontitis, $J$. Periodontol. 65 (1994), 379-386.

[17] P.I. Terasaki, R.S. Kaslick, T.L. West and A.I. Chasens, Low HLA-A2 frequency and periodontitis, Tissue Antigens $\mathbf{5}$ (1975), 286-288. 


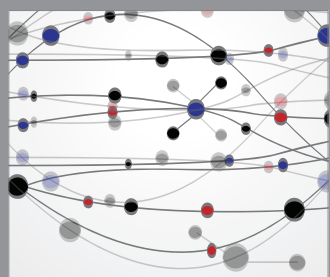

The Scientific World Journal
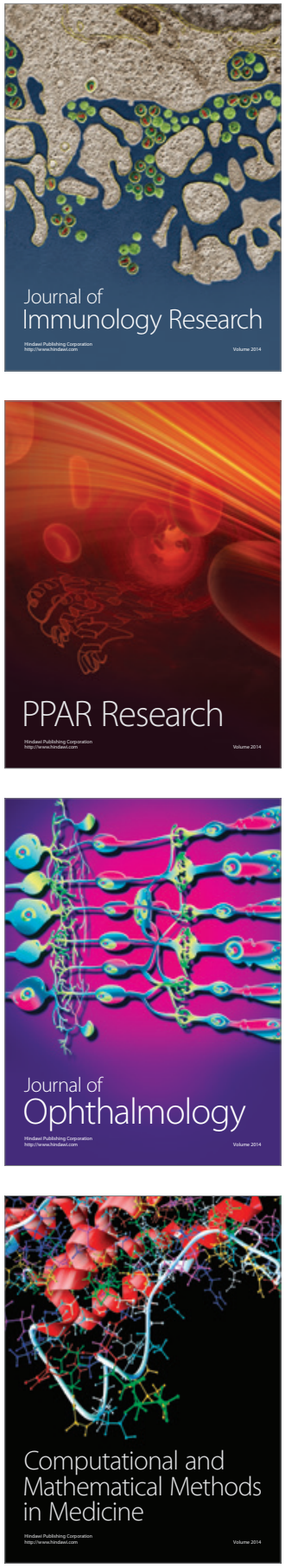

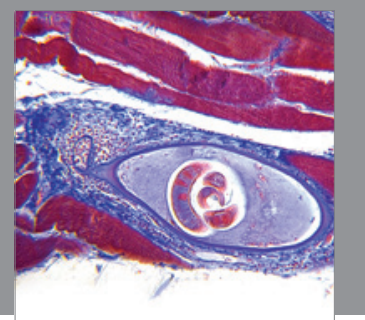

Gastroenterology

Research and Practice
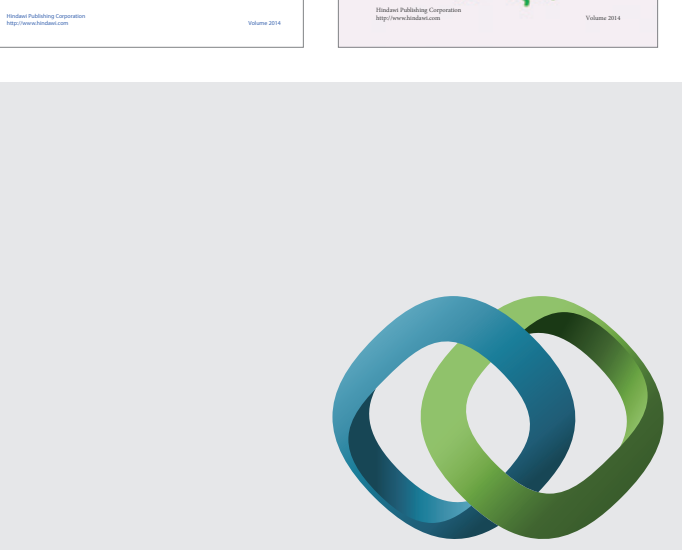

\section{Hindawi}

Submit your manuscripts at

http://www.hindawi.com
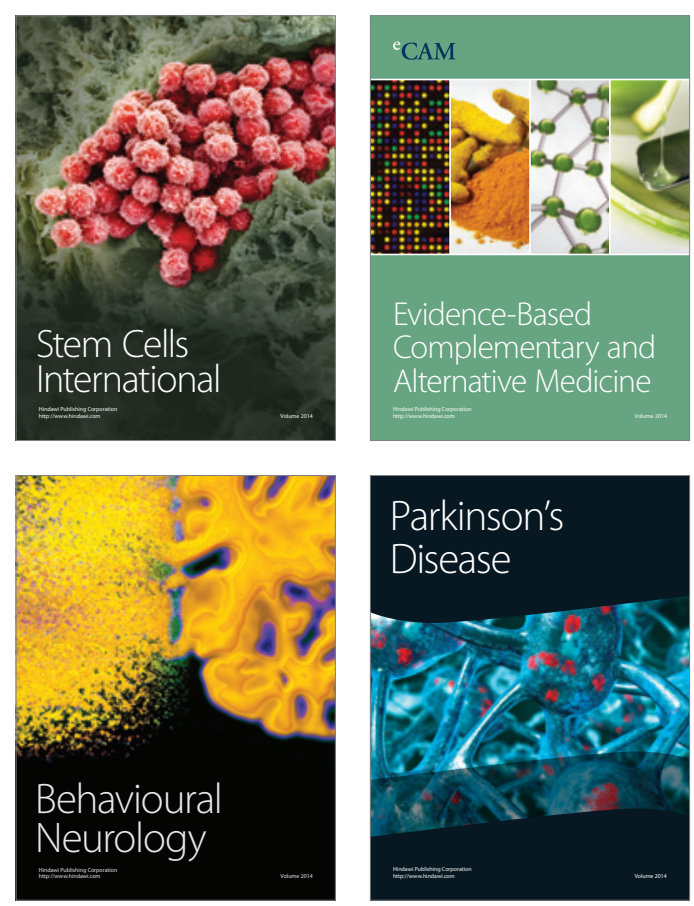

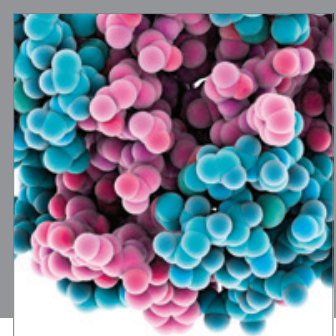

Journal of
Diabetes Research

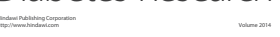

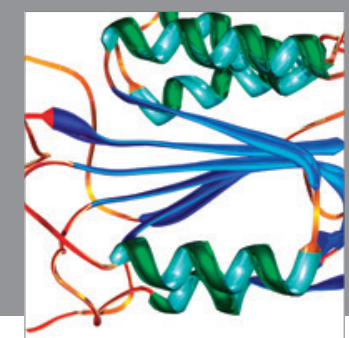

Disease Markers
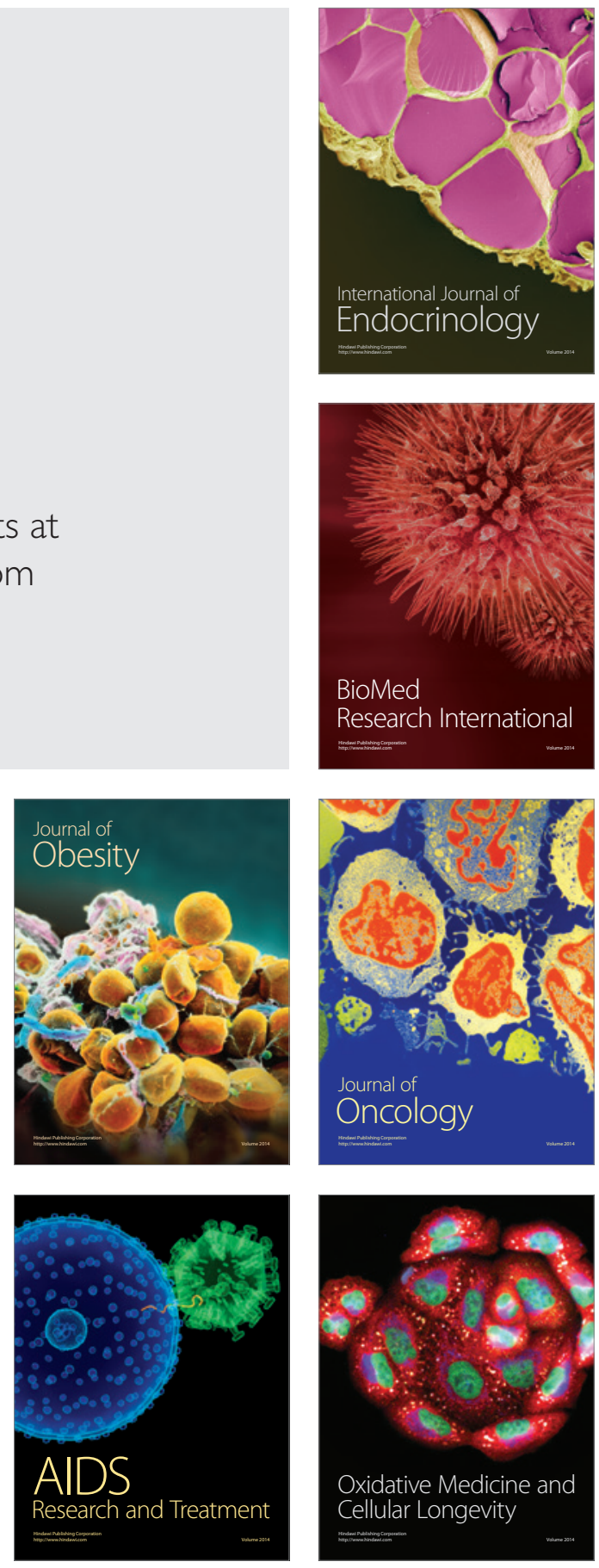